\title{
CUSTO DE PRODUÇÃO DO MARACUJÁ-AMARELO (Passiflora edulis) $^{1}$
}

\author{
FERNANDA DE PAIVA BADIZ FURLANETO2*, ADRIANA NOVAIS MARTINS ${ }^{2}$, \\ MAURA SEIKO TSTUSUI ESPERANCINI ${ }^{3}$, ANELISA DE AQUINO VIDAL ${ }^{2}$, FUMIKO OKAMOTO $^{2}$
}

RESUMO - Objetivou-se analisar economicamente a cultura do maracujá-amarelo (Passiflora edulis) na região de Marília-SP, safra de 2010/2011. Foram utilizadas estruturas do custo operacional efetivo e custo operacional total referente à fase de implantação e condução da lavoura por unidade de área e cinco indicadores de rentabilidade. Identificou-se um custo total de produção de $\mathrm{R} \$ 37.751,67$ por hectare ou $\mathrm{R} \$ 1,89$ por quilo da fruta. Os itens do custo operacional efetivo que mais oneraram o sistema de produção corresponderam às operações de máquinas $(31,1 \%)$ e mão de obra $(23,5 \%)$. Os indicadores de rentabilidade mostraram-se desfavoráveis para o sistema produtivo analisado, em decorrência, principalmente, do alto preço dos insumos e práticas para controle de doenças. Há necessidade de adequações técnicas relacionadas com o manejo fitossanitário da cultura para a redução do custo total de produção de modo a tornar a atividade rentável.

Termos para indexação: maracujazeiro, sistema sequeiro, custo operacional, indicador econômico, rentabilidade.

\section{COST OF PRODUCTION OF THE YELLOW PASSION FRUIT (Passiflora edulis)}

\begin{abstract}
The objective of this work was analyze the economic culture of yellow passion fruit (Passiflora edulis) in Marília-SP, the 2010/2011 crop year. Structures of effective operational cost and total operational cost of the culture per area unit were used to the phase of implementation and management of the crop per unit area and five indicators of profitability. Identified a total production cost of US\$23,743.19 per hectare or US\$ 1.19 per pound of fruit. The items of cost effective operating system that most burdened production corresponded to the operations of machinery (31.1\%) and labor $(23.5 \%)$. The profitability indicators proved to be unfavorable to the production system considered in due mainly to the high price of inputs and practices to control diseases. There is need for technical adjustments related to the handling of the crop plant to reduce the total cost of production in order to make the activity profitable.
\end{abstract}

Index terms: passion fruit cultivation, dry system, operational costs, economic indicator, profitability.

\section{INTRODUÇÃO}

A fruticultura representa um dos segmentos mais importantes da agricultura brasileira, respondendo, atualmente, por $25 \%$ do valor da produção agrícola nacional. O Brasil é o maior produtor mundial de maracujá, com aproximadamente $60 \%$ da produção total (ARÊDES et al., 2009). No País, a produção da fruta é estimada em 664.000 toneladas, sendo a área cultivada correspondente a 47.032 hectares por ano (IBGE, 2010). A produtividade média é de 12 a 15 toneladas por hectare, havendo potencial para produção de 30 a 35 toneladas por hectare (SILVA et al., 2009).

No Brasil, a produção da fruta destaca-se nas regiões Nordeste, Sudeste e Norte. Na região Sudeste, o maracujazeiro é uma das oito espécies frutíferas mais cultivadas no sistema extensivo, sendo precedido apenas pelas culturas da laranja, banana, limão, manga, tangerina, abacaxi e uva (SOUSA et al., 2008). Os Estados da Bahia, Espírito Santo e São Paulo são os maiores estados brasileiros produtores do maracujá. No Estado de São Paulo, a área cultivada é estimada em 3 mil hectares, e o valor de produção avaliado em 41 milhões de reais (ANUÁRIO DA AGRICULTURA BRASILEIRA, 2011).

\footnotetext{
${ }^{1}$ Trabalho Sinfruit 085 - Simpósio Internacional de Fruticultura - Avanços na Fruticultura (17 a 21 Outubro)

${ }^{2}$ Pesquisadora Científica, Agência Paulista de Desenvolvimento Tecnológico dos Agronegócios (APTA), Polo Centro Oeste Paulista, Unidade de Pesquisa de Marília, Rua Andrade Neves, no 81, Bairro Cascata, Marília-SP, CEP: 17.515.400, Tel. (14) 3433-0027. * Autora correspondente: fernandafurlaneto@apta.sp.gov.br.

${ }^{3}$ Professora, Faculdade de Ciências Agronômicas (FCA), Departamento de Gestão e Tecnologia Agroindustrial (DGTA), Universidade Estadual Paulista “Júlio de Mesquita Filho" (UNESP), Rua José Barbosa de Barros, n 1.780, Botucatu-SP, CEP: 18610-307
} 
Em 2009, a região de Marília ficou entre as seis maiores em área plantada no Estado de São Paulo, com 168 hectares e produção anual de 2.300 toneladas. No período de 2006 a 2009, as melhores médias de produtividade por ano no Estado foram obtidas nas regiões de Dracena (18,7 toneladas), Itapetininga (17,8 toneladas), Tupã (17,2 toneladas), Registro (17,1 toneladas), Sorocaba (16,8 toneladas) e Marília (13,3 toneladas) (TSUNECHIRO et al., 2011).

Objetivou-se com este trabalho estimar o custo de produção do maracujá-amarelo na região de Marília, atividade esta de caráter basicamente familiar, dada a escassez de informações regionais atualizadas sobre o cultivo de maracujazeiros, em um importante polo de produção da fruta no Estado de São Paulo.

\section{MATERIAL E METODOS}

Analisaram-se 16 municípios (Álvaro de Carvalho, Alvinlândia, Fernão, Gália, Garça, Lupércio, Marília, Ocauçu, Oriente, Oscar Bressane, Pompeia, Quintana e Vera Cruz) situados na área de abrangência do Escritório de Desenvolvimento Rural de Marília (EDR). O levantamento de campo foi realizado no período de fevereiro de 2010 a junho de 2011.

Os municípios de Fernão, Garça e Gália localizam-se na zona fisiográfica de Marília e possuem as principais lavouras de maracujá da região, apresentando o número de unidades de produção agrícola com cultivo de maracujá (UPas) e área cultivada com a fruta (hectare) equivalentes a $54 \mathrm{e}$ 85,2 em Fernão; 50 e 68,2 em Garça, e 17 e 56,3 em Gália, respectivamente.

A escolha dos municípios para a coleta dos dados econômicos foi realizada através da delimitação da área de estudo da atividade agrícola por meio da caracterização do limite geográfico da cadeia produtiva na região-alvo, que coincide com o critério de regionalização em mesorregiões.

$\mathrm{Na}$ escolha das propriedades, considerou-se o sistema de implantação e condução da lavoura (tecnologia representativa regionalmente), localização das áreas (quatro por município), ciclo produtivo (12 e 18 meses) e destino da produção (comercial). Foram selecionadas 12 (doze) propriedades para a obtenção das matrizes dos coeficientes técnicos.

A caracterização do principal sistema de produção do maracujá na região de Marília foi elaborada com base em informações coletadas por meio da aplicação de questionários, composto por perguntas semiestruturadas, junto a fruticultores situados nos municípios de Fernão, Garça e Gália. A localização das propriedades foi obtida através dos dados fornecidos pela Agência Paulista de Tecnologia dos Agronegócios (APTA), Coordenadoria de Assistência Técnica e Extensão Rural (CATI), Cooperativa Agrícola Central Sul Brasil e representantes comerciais afins. Os preços dos materiais, da mão de obra e dos serviços referem-se aos valores vigentes na cidade de Marília, atualizadas no mês de junho de 2011. A cotação do dólar correspondeu a $\mathrm{R} \$ 1,59$.

O clima regional, segundo a Carta Climática do Estado de São Paulo, baseada no sistema de Köeppen, é do tipo Cwa, com verão quente e inverno seco, a temperatura média do mês mais quente superior a $23^{\circ} \mathrm{C}$ e a do mês mais frio entre $-3^{\circ} \mathrm{C}$ e $18^{\circ} \mathrm{C}$. A precipitação pluviométrica média anual é $1.129 \mathrm{~mm}$, com deficiência hídrica anual da ordem de 50 a $80 \mathrm{~mm}$. O solo é classificado como Argissolo Vermelho-Amarelo eutrófico abrúptico, com textura arenosa/média, característico da forma de relevo suave ondulado a ondulado na região, com declives da ordem de 3 a $5 \mathrm{~cm} \mathrm{~m}^{-1}$.

O ciclo de produção do maracujazeiro-amarelo na região de Marília foi dividido em quatro fases: plantio (fevereiro), formação das plantas (março a setembro), florescimento (setembro a maio) e produção (novembro a julho). Os índices fitotécnicos e econômicos usados no estudo foram: a) ciclo de produção: 18 meses; b) época de plantio: fevereiro; c) espaçamento: $3,5 \mathrm{~m}$ entre linhas $X$ 3,0 m entre plantas; d) densidade de plantio: 952 plantas hecta$\mathrm{re}^{-1}$; muda: em tubete; e) altura média da muda: 10 $\mathrm{cm}$; f) produtividade: $20 \mathrm{t} \mathrm{ha}^{-1} ; \mathrm{g}$ ) período de colheita: novembro a julho; h) preço médio de venda da fruta: R \$ 1,75 (US\$ 1.10 ) por quilo (mesa) e R $\$ 0,60$ (US\$ 0.44 ) por quilo (indústria); i) comercialização: $60 \%$ para mesa e $40 \%$ para indústria; j) vida útil dos equipamentos: 10 anos; $\mathrm{k}$ ) pró-labore: um salário mínimo, que equivale a R $\$ 585,00$ (US\$ 367.92 ) mês $^{-1}$; 1) peso dos frutos por caixa: $13 \mathrm{~kg}$.

A metodologia utilizada para a estimativa do custo operacional de produção foi adaptada do Instituto de Economia Agrícola (IEA). As estruturas consideradas no sistema produtivo foram: Custo operacional efetivo $(C O E)=$ despesas efetuadas com mão de obra, operações de máquinas/equipamentos e materiais consumidos ao longo do processo produtivo; Custo operacional total $(C O T)=$ custo operacional efetivo acrescido dos gastos com a depreciação de máquinas, encargos financeiros (taxa de juros de $8,75 \%$ a.a. sobre $50 \%$ do COE durante o ciclo de produção); comissão pela comercialização (refere-se à comissão cobrada pela comercialização nas Companhias de Entrepostos e Armazéns Gerais de São Paulo $($ CEAGESP $)=16 \%$ sobre preço de 
venda) e despesa com frete (valor cobrado para transporte da fruta até o comprador $=\mathrm{R} \$ 0,22$ ou US\$ 0.19 por quilo da fruta transportada). As atividades analisadas compreenderam cinco etapas: preparo do solo, plantio, formação da lavoura, tratos culturais e operações relacionadas com a colheita.

Os indicadores dos resultados de rentabilidade adotados no trabalho foram os definidos em Martin et al. (1998), sendo eles:

a) Receita bruta $(\mathrm{RB})=$ Produtividade $x$ Preço médio de venda;

b) Receita líquida ou lucro operacional (RL ou LO) = Receita bruta - COT;

$X 100$;

c) Margem bruta $(\mathrm{MB})=(R B-C O T) / C O T$

d) Índice de lucratividade = Lucro operacional / Receita bruta;

e) Preço de equilíbrio $=$ COT $/$ Produtividade .

\section{RESULTADOS E DISCUSSÃO}

A atividade na região de Marília, no ano de 2011, foi explorada em propriedades com área total de 5 a 50 hectares, sendo a área média das lavouras comerciais de maracujá correspondente a 0,58 hectare. A cafeicultura, olericultura, pecuária de leite e corte foram as principais atividades desenvolvidas por agricultores familiares regionais, além da fruticultura.

As mudas são adquiridas em viveiros comerciais distribuídos nos municípios de Marília, Vera Cruz, Garça e Lupércio; entretanto, alguns fruticultores produzem as próprias mudas. A cultivar mais usada na região é a "Afruvec". O plantio ocorre, principalmente, na segunda quinzena de fevereiro com a utilização de mudas em tubetes. Os maquinários e implementos usados na instalação e condução da lavoura compreenderam: trator $(75 \mathrm{cv})$, roçadeira, pulverizador costal, carreta $(4.000 \mathrm{~kg})$, sulcador, atomizador $(400 \mathrm{~L})$ e tanque $(4.000 \mathrm{~L})$.

$\mathrm{O}$ cultivo de maracujazeiro-amarelo, em sua maioria, é implantado em locais anteriormente ocupados com pastagens, culturas anuais e/ou áreas de cafezais erradicados. Antes da implantação da cultura do maracujá, faz-se a dessecação do solo. Posteriormente, realiza-se a marcação do terreno e o sulcamento. A correção da acidez do solo e a adubação de plantio é feita no sulco. Antes do plantio, são instalados os mourões da espaldeira, bem como a cerca para proteção contra ataque de lebres. Após o plantio, faz-se a rega das mudas, adubação de cobertura na linha e colocação dos arames das espaldeiras. A manutenção da lavoura é feita por meio de capina manual na linha (coroamento), capina química na linha (entre plantas) e capina mecânica na entrelinha.
Faz-se a aplicação de fungicidas (preventivamente), inseticidas e acaricidas. Os antibióticos são utilizados apenas esporadicamente. Não é comum o monitoramento de pragas e doenças nos pomares.

Observou-se, no ciclo anual de florescimento do maracujazeiro, cerca de oito "picos" de florada, dos quais $60 \%$ dos picos produzem safras grandes, e $40 \%$, safras pequenas. A colheita é feita duas a quatro vezes por semana e consiste unicamente na coleta do fruto caído no chão. Normalmente, os frutos colhidos são acondicionados diretamente na carreta do trator. Posteriormente, são selecionados, classificados e embalados nas caixas de papelão $(13 \mathrm{~kg})$, onde consta o número de identificação do produtor, bem como o nome do destinatário. A comercialização, normalmente, é realizada por terceiros (intermediários).

De acordo com Andrade Junior et al. (2003), o adensamento de plantas em cultivos do maracujazeiro-amarelo é importante por propiciar maior rentabilidade em menor área. Esses autores avaliaram o efeito de diferentes densidades de plantio na produção, qualidade dos frutos e rentabilidade da cultura, em pomar comercial localizado no município de São Tiago-MG. Os tratamentos constituíram-se de diferentes espaçamentos na linha de plantio: $T_{1}, 1,0$ $\mathrm{m}$ (3.330 plantas ha-1 $) ; \mathrm{T}_{2}, 1,5 \mathrm{~m}$ (2.220 plantas ha $\left.^{-1}\right)$; $\mathrm{T}_{3}, 2,0 \mathrm{~m}\left(1.660\right.$ plantas ha $\left.^{-1}\right) ; \mathrm{T}_{4}, 3,0 \mathrm{~m}$ (1.100 plantas ha $\left.^{-1}\right)$, e $T_{5}, 4,0 \mathrm{~m}$ (830 plantas ha- $\left.{ }^{-1}\right)$. O espaçamento entre linhas foi de $3,0 \mathrm{~m}$ em todos os tratamentos. A maior produtividade foi estimada em $11,9 \mathrm{tha}^{-1}$ na densidade de 1.841 plantas ha ${ }^{-1}$. O adensamento não alterou a qualidade do fruto. A máxima eficiência econômica foi alcançada na densidade de 1.340 plantas $\mathrm{ha}^{-1}$, com rentabilidade de R $\$ 1.321,92$ por hectare.

Quanto à colheita, Vianna-Silva et al. (2008) ressaltaram a importância da colheita dos frutos ainda no pé, mesmo quando destinados para indústria, devido à tendência de aumento do rendimento do suco em até $40 \%$ quando as frutas apresentam aproximadamente $30 \%$ de cor amarela na casca.

Na região de Marília, o COT, para uma produtividade de $20 \mathrm{t} \mathrm{ha}^{-1}$, no sistema de sequeiro, a preços de maio de 2011, foi de R $37.751,67$ (US\$ $23,743.19$ ) por hectare ou $\mathrm{R} \$ 1,89$ (US\$ 1.19 ) por quilo da fruta. $\mathrm{O}$ total dos insumos representou $33,2 \%$ (R\$ 9.015,74 ou US\$ 5,670.28 por hectare) do COE (Tabela 1).

Segundo o Anuário da Agricultura Brasileira (2011), na região da Alta Paulista, ano de 2010, o COT do maracujá de sequeiro foi de $\mathrm{R} \$ 27.600,00$ (US\$ 15,681.82) por hectare por ano, levando em consideração uma produtividade de $30 \mathrm{t} \mathrm{ha}^{-1}$, e densidade de 500 plantas ha ${ }^{-1}$. Já, na região Centro- 
-Oeste paulista, o custo do maracujá irrigado foi de R \$ 42.708,00 (US\$ 24,265.91) ha ano ${ }^{-1}$, sendo a produtividade média de $38 \mathrm{t} \mathrm{ha}^{-1} \mathrm{e}$ densidade de 1.600 plantas ha-1 . Vê-se, portanto, que, na região de Marília, a produtividade observada foi inferior ao descrito nas regiões citadas acima, apesar de a densidade de plantas por hectare ter sido superior. No entanto, o custo de produção por unidade de área e por quilo da fruta apresentou-se superior em decorrência, provavelmente, da intensificação do uso de fungicidas preventivamente, prática esta que demanda maiores dispêndios com mão de obra, uso de maquinários, implementos e insumos.

Os itens do COE que mais oneraram o sistema de produção foram operações de máquinas $(31,1 \%)$ e mão de obra $(23,5 \%)$. Os itens correspondentes à depreciação de máquinas, encargos financeiros, comissão de comercialização e despesa com frete representaram $28,2 \%$ do COT, indicando que esses custos devem ser sempre incluídos no custo total de produção em virtude da significativa participação econômica, no custo operacional, na cultura de maracujazeiros.

Hafle et al. (2010) estudaram a rentabilidade econômica do maracujazeiro-amarelo no município de Lavras-MG, sob diferentes formações da planta e, também, observaram que o item mão de obra é representativo no COT da fruta. Esses mesmos autores identificaram que a receita líquida, por hectare, em dois anos, oscilou entre -R \$ 4.570,50 (-US\$ $2.874,53$ ) a $\mathrm{R} \$ 3.895,74$ (US\$ 2450,15). O índice de rentabilidade variou de 0,89 a 1,37.

Na região de Marília, os indicadores de rentabilidade mostraram-se desfavoráveis no sistema produtivo analisado, considerando a produtividade de $20 \mathrm{t} \mathrm{ha}^{-1}$, bem como a qualidade e destino da produção (60\% mercado e $40 \%$ indústria) (Tabela 2). A receita bruta, por ciclo e por hectare, correspondeu a R \$ 26.600,00 (US\$ 16,729.56). A margem bruta, após cobrir as despesas do COE e COT, apresentou percentual de $-29,5 \%$. O índice de lucratividade, que equivale à relação entre o lucro operacional e a receita bruta, em percentagem, foi de $-41,92 \%$. Já, o ponto de nivelamento corresponde a $28,3 \mathrm{t} \mathrm{ha}^{-1}$. Portanto, para cobrir todas as despesas realizadas durante o ciclo produtivo, faz-se necessário produzir 2,29 cx. planta $^{-1}$, produção esta viável em locais onde não ocorre alta incidência de ataque de viroses.

Lima et al. (2009) analisaram a rentabilidade do maracujá em seis polos produtivos brasileiros (Benevides-PA, Araguari-MG, Itapuranga-GO, Região Integrada de Desenvolvimento do Distrito Federal e Entorno-RIDE, Bom Jesus da Lapa-BA e Vera Cruz- SP) e observaram que a cultura do maracujazeiro-amarelo é viável economicamente nos polos quando a produtividade é superior a 19 t ha ano $^{-1}$. Todavia, devido ao aumento acentuado do preço dos insumos e o preço estável do quilo da fruta nos últimos 05 anos (média de $\mathrm{R} \$ 1,61 \mathrm{~kg}^{-1}$ ou US\$ $1.01 \mathrm{~kg}^{-1}$ ), torna-se necessário aumentar a produtividade por hectare, bem como minimizar as entradas financeiras para fazer com que a atividade seja sustentável economicamente.

Já, Motta et al. (2008) identificaram para a cultura de maracujazeiro em sistema convencional, no município de Maringá-PR, com produtividade de 17 tha ano ${ }^{-1}$, uma receita bruta de $\mathrm{R} \$ 14.616,30$ (US\$ $5.433,57$ ) e lucro operacional de R $\$ 6.110,15$ (US\$ 2,271.43), por hectare. Já, o índice de lucratividade correspondeu a $41,83 \%$, e o preço de equilíbrio, de $\mathrm{R} \$ 0,57 \mathrm{~kg}^{-1}$.

$\mathrm{Na}$ região Norte Fluminense, Ponciano et al. (2005) verificaram que o cultivo do maracujá é viável economicamente. Dentre as frutas analisadas, as maiores taxas internas de retorno foram encontradas para o maracujá, graviola, abacaxi e pinha. A variável com maior efeito sobre a rentabilidade foi o preço de venda do produto, bem como o custo da mão de obra e o preço dos fertilizantes. $\mathrm{O}$ cultivo do abacaxi, coco, pinha, maracujá e graviola praticamente não ofereceram riscos econômicos. Os maiores riscos foram observados na cultura da manga e goiaba. Concluiu-se que a importância do custo da mão de obra na determinação do resultado financeiro dos sistemas produtivos é reflexo direto da grande exigência desse fator ao longo do ciclo de produção na fruticultura. Portanto, além dos aspectos econômicos analisados, decorrentes da expansão da fruticultura nessa região, esta atividade, intensiva em mão de obra, gera benefícios sociais mediante criação de empregos. A comercialização do produto foi apontada como um dos principais problemas da fruticultura. 
TABELA 1- Estimativa do custo operacional de produção do cultivo de maracujá-amarelo, por ciclo/hectare, região de Marília, Estado de São Paulo, ano de 2011.

\begin{tabular}{lrrrr}
\multicolumn{5}{c}{ (em real e dólar) } \\
Item & $\mathbf{R} \$$ & US\$ & $\mathbf{\%}$ COT & \% COE \\
\hline Mão de obra & $6.380,16$ & $4,012.68$ & 16,9 & 23,5 \\
Mudas & 525,00 & 330.19 & 1,4 & 1,9 \\
Calcário & 180,00 & 113.21 & 0,5 & 0,7 \\
Adubo & $5.050,64$ & $3,176.50$ & 13,4 & 18,6 \\
Fungicida & $2.182,90$ & $1,372.89$ & 5,8 & 8,1 \\
Inseticida + formicida & 665,90 & 418.81 & 1,8 & 2,5 \\
Acaricida & 162,80 & 102.39 & 0,4 & 0,6 \\
Antibiótico & 100,50 & 63.21 & 0,3 & 0,4 \\
Herbicida & 148,00 & 93.08 & 0,4 & 0,6 \\
Materiais em geral & $3.276,00$ & $2,060.38$ & 8,7 & 12,1 \\
Operações de máquinas & $8.444,52$ & $5,311.02$ & 22,4 & 31,1 \\
Custo op. efetivo (COE) & $\mathbf{2 7 . 1 1 6 , 4 2}$ & $\mathbf{1 7 , 0 5 4 . 3 5}$ & $\mathbf{7 1 , 8}$ & $\mathbf{1 0 0 , 0}$ \\
Depreciação de máquinas & $1.688,90$ & $1,062.20$ & 4,5 & \\
Encargos financeiros & $1.186,34$ & 746.13 & 3,1 & \\
Comissão comercialização & $3.360,00$ & $2,113.21$ & 8,9 & \\
Despesa com frete & $4.400,00$ & $2,767.30$ & 11,7 & \\
Custo op. total (COT) & $\mathbf{3 7 . 7 5 1 , 6 7}$ & $\mathbf{2 3 , 7 4 3 . 1 9}$ & 100,0 & \\
Custo op. por unidade & $\mathbf{1 , 8 9}$ & $\mathbf{1 . 1 9}$ & & \\
\hline
\end{tabular}

TABELA 2- Indicadores de rentabilidade do cultivo de maracujá-amarelo, por ciclo/hectare, região de Marília, Estado de São Paulo, ano de 2011.

\begin{tabular}{lrr}
\hline Indicador & Unid. & Maracujá \\
\hline Produtividade & $\mathrm{kg} \mathrm{ha}^{-1}$ & 20.000 \\
Venda para mercado & $\mathrm{t} \mathrm{ha}^{-1}$ & 12.000 \\
Venda para indústria & $\mathrm{t} \mathrm{ha}^{-1}$ & 8.000 \\
Preço médio ponderado & $\mathrm{R} \$ \mathrm{~kg}^{-1}$ & 1,33 \\
Preço médio ponderado & $\mathrm{US} \$ \mathrm{~kg}^{-1}$ & 0.84 \\
Receita bruta & $\mathrm{R} \$ \mathrm{ha}^{-1}$ & $26.600,00$ \\
Receita bruta & $\mathrm{US} \$ \mathrm{ha}^{-1}$ & $16,729.56$ \\
Receita líquida & $\mathrm{R} \$ \mathrm{ha}^{-1}$ & $-11.151,67$ \\
Receita líquida & $\mathrm{US} \$ \mathrm{ha}^{-1}$ & $-7,013.63$ \\
Margem bruta & $\%$ & $-29,54$ \\
Índice de lucratividade & $\%$ & $-41,92$ \\
Ponto de nivelamento & $\mathrm{t} \mathrm{ha}^{-1}$ & 28.385 \\
Ponto de nivelamento & $\mathrm{cx} \mathrm{pl}^{-1}$ & 2,29 \\
\hline
\end{tabular}




\section{CONCLUSÃO}

1. O sistema de condução dos pomares de maracujá-amarelo na região de Marília-SP, principalmente nas operações de controle fitossanitário, que ocorre sem orientação técnica, bem como o alto custo dos insumos, comprometeu a viabilidade da atividade no ano de 2010/2011, levando em consideração a produtividade e o preço médio de venda analisado nesta pesquisa. A adoção de técnicas de manejo integrado de pragas e doenças, que tendem a utilizar menos insumos, poderá reduzir o custo total de produção, de modo a tornar a atividade rentável.

2. Vale ressaltar que, em um ambiente cada vez mais competitivo, no qual está inserido o setor agrícola, faz-se necessária a adoção de técnicas de gestão, principalmente no que tange à estrutura de custos operacionais e de transação, para refletir em ganhos de competitividade.

\section{REFERÊNCIAS}

ANDRADE JUNIOR, V.C.A.; ARAÚJO NETO, S.E.; RUFINI, J.C.M.; RAMOS, J.D. Produção de maracujazeiro-amarelo sob diferentes densidades de plantio. Pesquisa Agropecuária Brasileira, Brasília, v.8, n.12, p.1381-1386, 2003.

ANUÁRIO DA AGRICULTURA BRASILEIRA. Maracujá. São Paulo: Agra FNP Pesquisas, 2011. p.387-391.

ARÊDES, A.F.; PEREIRA, M.W.G.; GOMES, M.F.M.; RUFINO, J.L.S. Análise econômica da irrigação na cultura do maracujá. Revista de Economia da Universidade Estadual de Goiás, Anápolis, v.5, n.1, p.66-86, 2009.

HAFLE, O.M.; RAMOS, J.D.; ARAÚJO NETO, S.E.; MENDONÇA, V. Rentabilidade econômica do cultivo do maracujazeiro-amarelo sob diferentes podas de formação. Revista Brasileira de Fruticultura, Jaboticabal, n.32, v.4, p.1082-1088, 2010.

IBGE - Instituto Brasileiro de Geografia e Estatística. Dados demográficos e produção agrícola municipal. Rio de Janeiro, 2010. 387p.
LIMA, M.M.; AZEVEDO, D.B.; SANTOS JUNIOR, S. Comparativo da rentabilidade da produção de maracujá em seis polos no Brasil. Revista Inovação, Gestão e Produção, Santa Maria-RS, v.1, n.5, p.54-69. 2009.

MARTIN, N.B.; SERRA, R.; OLIVEIRA, M.D.M.O.; ÂNGELO, J.A.; OKAWA, H. Sistema integrado de custos agropecuários - CUSTAGRI. Informações Econômicas, São Paulo, v.28, n.1, p.7-28, 1998.

MOTTA I.S.; CUNHA, F.A.D.; SENA, J.O.A.; CLEMENTE, E.; CALDAS, R.G.; LORENZETTI, E.R. Análise econômica da produção do maracujazeiro-amarelo em sistema orgânico e convencional. Ciência e Agrotecnologia, Lavras, v.32, n.6, p.19271934, 2008.

PONCIANO, N.J.; SOUZA, P.M.; MATA, H.T.C.; VIEIRA, J.R.; MORGADO, I.F. Análise de viabilidade econômica e de risco da fruticultura na região norte Fluminense. Revista de Economia e Sociologia Rural, Brasília, v. 42, n.4, p.615-635, 2005.

SILVA, C.B.M.C.; SILVA, C.B.C.; NONATO, J.V.; CORRÊA, R.X.; OLIVEIRA, A.C. Genetic dissimilarity of "yellow" and "sleep" passion fruit accessions based on the fruits physical-chemical characteristics. Crop Breeding and Applied Biotechnology, Viçosa, MG, n.9, v.3, p.210-218, 2009.

SOUZA, P.M.; FERREIRA, V.R.; PONCIANO, N.J.; BRITO, M.N. Otimização econômica, sob condições de risco, para agricultores familiares das regiões norte e noroeste do Estado do Rio de Janeiro. Revista Pesquisa Operacional, Rio de Janeiro, v.28, n.1, p.123-139, 2008.

TSUNECHIRO, A.; COELHO, P.J.; CASER, D.V.; BUENO, C.R.F.; PINATTI, E.; CASTANHO FILHO, E.P.; BINI, D.L.C. Valor da produção agropecuária no Estado de São Paulo em 2010. Informações Econômicas, São Paulo, v.41, n.5, p.71-83, 2011.

VIANNA-SILVA, T.; RESENDE, E.D.; PEREIRA, S.M.F.; VIANA, A.P.; ROSA, R.C.C.; VITORAZI, L. Influência dos estádios de maturação sobre as características físicas dos frutos de maracujá-amarelo. Bragantia, Campinas, v.67, n.2, p.267-273, 2008. 